\title{
Study on Major Health Problems and Constraints of Dairy Cattle in and Around Hawassa Town
}

\author{
Natnael Debebe ${ }^{1}$ and Haben Fesseha*2 \\ ${ }^{1}$ Chagni city administration, Agriculture office, Awi zone of Amhara region, Ethiopia \\ ${ }^{2}$ School of Veterinary Medicine, WolaitaSodo University, Ethiopia
}

*Corresponding author: Haben Fesseha, School of Veterinary Medicine, WolaitaSodo University, WolaitaSodo, Ethiopia

\section{ARTICLE INFO}

Received: 慧 August 29, 2020

Published: 蔧 September 08, 2020

Citation: Natnael Debebe, Haben Fesseha. Study on Major Health Problems and Constraints of Dairy Cattle in and Around Hawassa Town. Biomed J Sci \& Tech Res 30(1)-2020. BJSTR. MS.ID.004905.

Keywords: Dairy Farms; Constraints; Health Problems; Hawassa; Ethiopia

\section{ABSTRACT}

A crossectional study was conducted to identify the major health problems of dairy cattle and associated risk factors in and around Hawassa Town, Southern Ethiopia. A total of 340 randomly selected dairy herd attendants or owners were visited and interviewed using a pre-tested and structured questionnaire. The study herds composed of lactating (573), pregnant (262), and dry cows (91), and heifers (279). The major health problems of dairy cows in the study area were LSD (42.6\%), repeat breeding (41.8\%), mastitis (25.3\%), milk fever $(22.4 \%)$, diarrhea $(29.1 \%)$, bloat $(16.5 \%)$, respiratory problems $(23.2 \%)$ and FMD (16.5\%). Other diseases such as vaginal and uterine prolapsed (13.5\%), RFM (13.2\%), dystocia (7.6\%), and ectoparasites (12.4\%) were encountered with low prevalence. The risk factors that had a significant association with selected health problems include breed, production system, hygienic status, deworming per year, water source, herds size, and watering frequency. For example, the GIT problems had a significant difference with large herd size, poor hygienic status, and semi-intensive production system and decreased deworming per year with $(\mathrm{P}<0.05)$. Infectious diseases such as FMD and LSD had significantly higher occurrence with large herd size, poor hygiene, reduced drinking water frequency, crossbreed herds, and those herds using river water $(\mathrm{P}<0.05)$. Thus, it is recommended that improved animal husbandry especially health management should be in place to minimize the occurrence of major health problems to increase the production and productivity of dairy cows in the study area.

\section{Introduction}

Cattle production is the main component of agricultural growth in many parts of sub-Saharan countries. The overall cost of keeping farm animals is mainly attributable to health care, nutrition, and reproduction management. However, these inputs to the livestock production have not yet matched to the desired contribution of smallholder farms to the livelihood and economy of the people in subSaharan countries. As in many other countries, livestock, particularly cattle play an important role in Ethiopia as being a source of milk, meat, hide, and source of draught power [1]. The predominant livestock production system in Ethiopia is extensive, where indigenous breeds are kept under low-input/low-output husbandry practices. The productivity of this sector is constrained by several factors of which health problems are among the top constraints [2].
Smallholder dairy farmers produce the bulk of milk available for processing. Milk and milk products play a very important role in feeding the rural and urban population of Ethiopia and have a high nutrition value and are daily produced, sold for cash, or readily processed.

It is a cash crop in the milk-shed areas that enables families to buy other foodstuffs, contributing significantly to household food security. Given the long tradition of using milk and milk products by the Ethiopian society, no doubt increasing smallholder dairy production and productivity would bring about a conspicuous impact on improving the welfare of women, children, and the nation's population at large $[3,4]$. Despite its potential for dairy development, the productivity of the dairy sector in Ethiopia is 
generally low and the direct contribution it makes to the national economy is limited. For example, in 2009 average cow milk production was estimated at only 1.54 liters per cow per day [2] and the sector is characterized by low productivity and the income derived from this sector of agriculture's could not impart significant role in the development of the country's economy [5]. This was due to the fact that dairy production has been hampered by multi-faceted, production system-specific constraints related to genotype, feed resources, and feeding systems, access to services and inputs, low adoption of improved technologies, marketing and absence of clear policy support to the sector [6]. Peri-urban dairy farming is a growing business in Ethiopia in response to increasing urbanization and demand for milk and milk products. But the productivity of the sector is generally low due to constraints of diseases, scarcity of feed, insufficient AI and veterinary services, low inputs (inadequate management), and poor performance of indigenous breeds.

Less than $1 \%$ of the cattle populations of Ethiopia are exotic or crossbred dairy cows $[7,8]$. Feed scarcity is the main constraint limiting livestock productivity in the country and there are seasonal fluctuations in feed supply in both quantity and quality. Feed shortage and nutrient deficiency are common during the dry season in both highlands and lowlands of the country. Various factors contribute to the low feed supply to livestock. Grazing lands are decreasing due to the human population increment and increasing conversion of grazing land into croplands [9]. Poor soil fertility and unreliable and seasonal fluctuations of rainfall limit the amount of feed obtained and crop residues are low in nutritive value. The use of improved forages by smallholder farmers is not common and the utilization of agro-industrial by-products is limited to urban and peri-urban areas. Currently, with increasing human population and demand for crop production, grazing lands are shrinking. Besides, livestock are kept in low potential lands that are not suitable for crop production and other purposes [10]. Reproductive disorders are among the most common problems affecting the production and productivity of dairy cows $[1,11]$. The presence of the reproductive problems result in considerable economic loss to the dairy industry due to lesser number of calves crop, slower uterine involution, prolonged inter-conception and calving interval, early depreciation of potentially used cows, decreased milk yield per lactation as well as overall lifetime production, and increased costs due to veterinary services and earlier culling of cows [12]. Health problems in dairy cows cause production Losses $[4,13]$.

The incidence of health disorders has increased, possibly because they are associated with increased milk yield and production stress, as well as mortality rates (from 2 to $3.5 \%$ in 10 years), with locomotor disorders as one of the main causes [14]. Dystocia is one of the important reproductive health problems of dairy cows that are commonly known as parturition [15]. It has been estimated that between 2 and $23 \%$ of cows in a herd experience difficult calving that require farmer or veterinarian assistance [16]. In Ethiopia, genetics is the main constraint to dairy cattle. The livestock genetic resources of Ethiopia have been involved largely as a result of natural selection influenced by environmental factors. This has made the stock better adapted to feed and water shortages, disease challenges, and harsh climates. However, the dairy industry is not developed as that of other East African countries such as Kenya, Uganda, and Tanzania $[17,18]$. In general, diseases of various origins (viral, bacterial, and parasites) have been reported as a major constraint of food animal production and productivity in various parts of the world. Therefore, the efficient production of livestock that yields milk, meat, and drought power is a major concern of society [19]. Similarly, smallholder dairy farms in and around Hawassa are also affected by a wide range of health problems that constrain their production and reproduction performances. This study aims to investigate the major health problems and its potential risk factors associated with dairy herds in and around Hawassa.

\section{Materials and Methods}

\section{Study Area}

A cross-sectional study was conducted from November 2016 up to March 2017 in and around Hawassa city, which is located in $275 \mathrm{~km}$ south of Addis Ababa. It is the capital city of south nation nationalities of people's regional state which is one of the high potential areas for dairy farm production in the region. Hawassa is situated at an altitude of $1750 \mathrm{~m}$ above sea level and it is found at 6 to $70 \mathrm{~N}$ and 38-380 E. The area receives an average annual rainfall of $955 \mathrm{~mm}$ and the mean annual temperature of $20^{\circ} \mathrm{C}$ [20].

\section{Study Population}

The study animals were different breeds of cattle that is local, exotic, and crossbreed. The study includes dairy cows of different parity, age group, body condition, management, lactating pregnant, lactating non-pregnant, dry pregnant, and dry non-pregnant dairy cows were included during this questionnaire survey. Besides, pregnant cows at any trimester stage were purposively selected for regular follow up during the study period. Classification of farm management systems was performed according to the criteria adopted by Molalegne, et al. [21]. In this study, local, cross, breeds were included in the study of animals. Dairy is kept for milk production as sources of income, home consumption, and different purposes. Animals were kept under intensive, semi-intensive and extensive management systems in Hawassa and surrounding towns. Similarly, study cows were kept under different hygienic conditions of the house, feeding sources, and water sources were included.

\section{Study Design and Methodology}

A cross-sectional study was conducted to investigate the health problems/diseases/ and management conditions of the animals in 
the area. A total of 340 herds (owners or attendants of dairy cows) rearing dairy cattle were randomly selected and interviewed using a structured questionnaire. Data regarding feeding, water source, hygiene, herd size, deworm per year, frequency of drinking per day, health management, breeding method, feed sources, and production system were recorded through a structured questionnaire in the study. During the interview about the health problems of the herd and the numbers of diseased animals in each disease were recorded. In the questionnaire, the major health problems such as udder, reproductive, respiratory, GIT, and other system problems and some risk factors in the herd were recorded.

\section{Sampling Size and Sampling Method}

In and around Hawassa city, were considered as sampling frame from which dairy cattle 340 herds were selected through simple random sampling. The sample size for the current study was determined according to Thrusfield [22]. The expected prevalence $(33.6 \%)$ was based on a previous study report on major health problems of dairy farms in Hawassa [23].

Where:

$$
n=\frac{1.96^{2} * P \exp (1-P \exp )}{d^{2}}
$$

$\mathrm{n}=$ required sample size

Pexp $=$ expected prevalence $(\mathrm{P}=33.6 \%)$.

$\mathrm{d}=$ desired absolute precision.

$\mathrm{Z}=1.96$ for $95 \%$ confidence interval.

A total of 340 dairy herds(farms) were randomly selected for the study.

\section{Data Management and Statistical Analysis}

The raw data collected from the inquiry were entered into Microsoft Excel 2016 spreadsheet. Data were coded and filtered for any invalid entry then transferred to Stata 11 version for statistical analysis. The descriptive statistics such as frequency and percentage were generated using figures and tables. Different GIT, reproductive, infectious diseases, and related problems were respectively added together as counts of affected animals per herds. Then, Poisson regression was used to analyze the association of selected risk factors with major health problems (GIT, Reproductive, and other infectious diseases) affecting dairy cows at the herd level. A 95\% Confidence interval and a significance level of $\mathrm{P}<0.05$ was set.

\section{Results}

From the total 340 herds (respondents) half of the herds were local (50.9\%), the remaining were cross and exotic breeds which had $32.9 \%$ and $16.2 \%$ respectively. Above half of the sample respondents' practice, the intensive production system was (52\%) while others around $25.9 \%$ and $22.1 \%$ were managed semiintensively and extensively. Most of the respondents managed the cattle under the intensive system. This could reduce the transmission of diseases and improves animal managing systems. The hygienic conditions of the houses were judged and the majority was under medium or fair which were $68.5 \%$ and others $15.9 \%$ and $15.6 \%$ were under good and poor conditions. The majority were under medium conditions that might be due to frequent cleaning of the houses, usage of modern types of houses, and small numbers of animals in the herds. Tap water, well and rivers were the source of water in the study area. But, the majority of the respondents used tap water including boreholes (67.7\%) since most of the herds were kept under an intensive production system. While the rest $22.1 \%$ and $10.3 \%$ of the respondents used the river as well as the source of water for animals respectively. The herds received water once per day was (44.4\%) while $55.6 \%$ of the herds received water twice a day. Most of the farms had below 6 animals (67.4\%) and while others had between 6 and 10 animals (24.1\%), and few farms keep more than 10 animals per farm (8.5\%). As summarized in Table 1, different health problems and diseases observed during the visit were LSD (42.6\%), Repeat Breeding (41.8\%), Diarrhea (29.1\%), Mastitis (25.3\%), Respiratory Problems (23.2\%), Milk Fever (22.4\%), FMD (16.5\%), RFM (13.2\%), Simple Indigestion (12.6\%) and Bloats (16.5\%) were recorded at the herd level. Similarly, animal level disease occurrences showed the prevalence of LSD (18.6\%), mastitis (14.5\%), milk fever (10.3\%), FMD (9.2\%), diarrhea $(9.2 \%)$ and repeat breeding (15.1\%) were recorded.

Other diseases with low occurrences at animal level include teat trauma $(3.8 \%)$, blind teat $(4.8 \%)$, respiratory problems (8.8\%), indigestion (4.6\%), bloat (5.5\%), retained fetal membrane (5.5\%), Dystocia (3.2\%), prolapsed (5.2\%), ectoparasite (4.8\%). The prevalence and frequency of diseases both at the herd and individual animal level were summarized below in Table 1. Different potential risk factors collected during the visit were used to assess their association with aggregated disease groups. These variables including production system, water source, hygienic condition, herd size, and others were considered as factors affecting GIT and reproductive related health problems and occurrences of other infectious diseases at the herd level. For example, significant associations have been observed between occurrences of FMD and LSD with various risk factors. The two diseases were more prevalent in those herds keeping cross breeds, herd size above 5, poor hygienic conditions, herds using water from river sources, and herds provided once a day were highly associated (Table 2). Herd belongs to semi-intensive management had higher GIT health problems compared to those in intensive management. Herd size between 6 to 10 and above 10 numbers of cows had high significance with GIT problems. Herds categorized under poor hygienic conditions had an association with GIT problems. Infectious diseases such as FMD and LSD had highly associated with a water source, hygienic condition of the herds, frequency of deworming, and herd size. The study population proportion in (\%) of the total animals in 340 herds includes dry, pregnant, heifers, and lactating (Figure 1). 


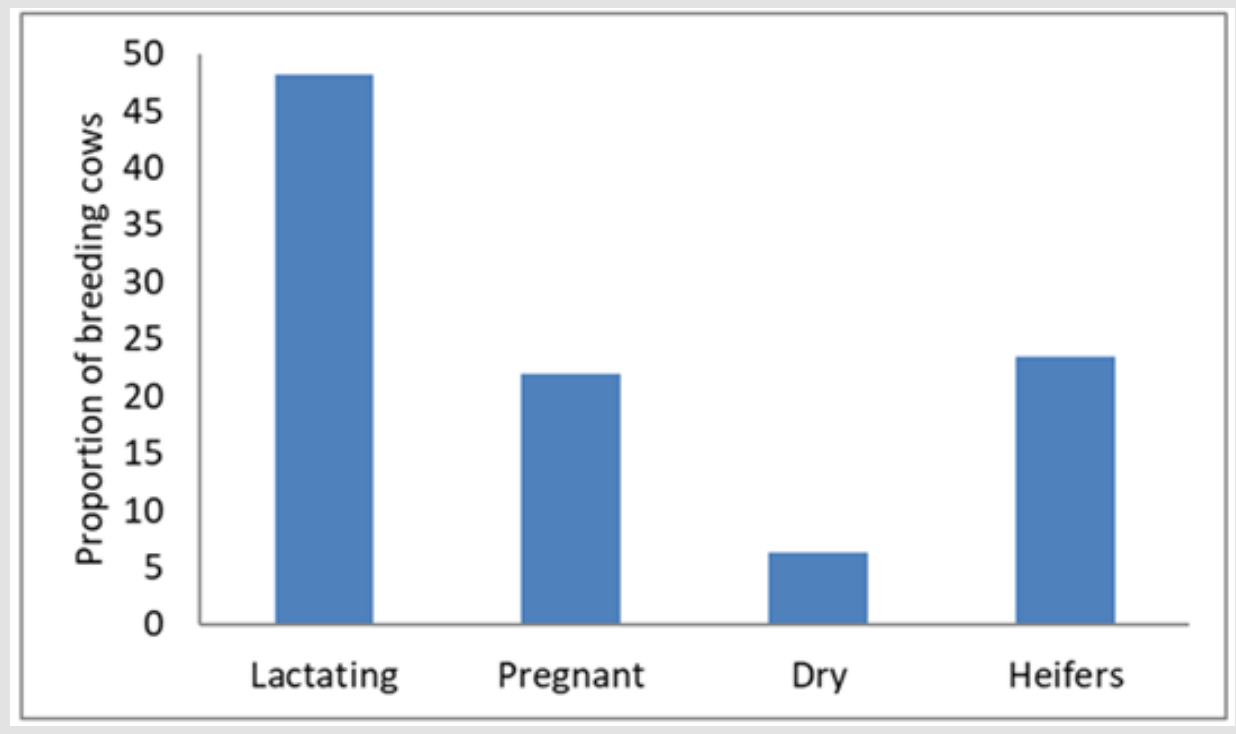

Figure 1: The proportion of study animals (dry, lactating, pregnant, and heifers) in (\%).

Table 1: Occurrences of different health problems at herd and cows levels.

\begin{tabular}{|c|c|c|c|c|}
\hline \multirow{2}{*}{ Diseases } & \multicolumn{2}{|c|}{ Herd level } & \multicolumn{2}{|c|}{ Animal level } \\
\hline & No & Prevalence & No & Prevalence \\
\hline \multicolumn{5}{|c|}{ Udder Problems } \\
\hline Mastitis & 86 & 25.3 & 132 & 14.5 \\
\hline Teat trauma & 26 & 7.6 & 35 & 3.8 \\
\hline Blind teat & 34 & 10 & 44 & 4.8 \\
\hline \multicolumn{5}{|c|}{ Reproductive } \\
\hline RFM & 45 & 13.2 & 50 & 5.5 \\
\hline Dystocia & 26 & 7.6 & 29 & 3.2 \\
\hline Abortion & 17 & 5 & 24 & 2.6 \\
\hline Stillbirth & 10 & 2.9 & 10 & 1.1 \\
\hline Uterine \& vaginal prolapsed & 46 & 13.5 & 47 & 5.2 \\
\hline Repeat breeding & 142 & 41.8 & 180 & 15.1 \\
\hline Milk fever & 76 & 22.4 & 94 & 10.3 \\
\hline \multicolumn{5}{|c|}{ GIT Problems } \\
\hline Diarrhea & 99 & 29.1 & 110 & 9.2 \\
\hline Foreign material & 37 & 10.9 & 42 & 3.5 \\
\hline Indigestion & 43 & 12.6 & 55 & 4.6 \\
\hline Constipation & 21 & 6.2 & 27 & 2.3 \\
\hline Acidosis & 14 & 4.1 & 14 & 1.2 \\
\hline Bloat & 56 & 16.5 & 65 & 5.5 \\
\hline \multicolumn{5}{|c|}{ Other Diseases } \\
\hline Lameness & 26 & 7.6 & 30 & 2.5 \\
\hline Respiratory & 79 & 23.2 & 105 & 8.8 \\
\hline Loss of hair & 33 & 9.7 & 35 & 2.9 \\
\hline Ectoparasite & 42 & 12.4 & 57 & 4.8 \\
\hline FMD & 56 & 16.5 & 110 & 9.2 \\
\hline LSD & 145 & 42.6 & 221 & 18.6 \\
\hline
\end{tabular}


Table 2: Multivariable Poisson regression of herd-level GIT and Reproductive problems, and other infectious diseases (breeding cows were regarded as exposure variable).

\begin{tabular}{|c|c|c|c|c|c|c|c|c|}
\hline \multirow{2}{*}{ Variables \& Levels } & \multicolumn{4}{|c|}{ GIT Problems } & \multicolumn{2}{|c|}{$\begin{array}{l}\text { Reproductive Prob- } \\
\text { lems }\end{array}$} & \multicolumn{2}{|c|}{ FMD \& LSD } \\
\hline & Herds & Percent & Coef. & p-value & Coef. & p-value & Coef. & p-value \\
\hline \multicolumn{9}{|c|}{ Breed } \\
\hline Exotic & 55 & 16.2 & & & & & & \\
\hline Cross & 112 & 32.9 & -0.28 & 0.186 & 0.04 & 0.786 & -0.41 & 0.031 \\
\hline Local & 173 & 50.9 & -0.71 & 0.173 & -1.03 & 0.077 & -0.25 & 0.65 \\
\hline \multicolumn{9}{|c|}{ Management System } \\
\hline Intensive & 177 & 52.1 & & & & & & \\
\hline Semi-intensive & 88 & 25.9 & 1.09 & 0.022 & 0.13 & 0.822 & 0.37 & 0.465 \\
\hline Extensive & 75 & 22.1 & 0.35 & 0.489 & -0.62 & 0.312 & 0.02 & 0.971 \\
\hline \multicolumn{9}{|c|}{ Water Source } \\
\hline Tap water & 230 & 67.7 & & & & & & \\
\hline Well & 35 & 10.3 & 0.14 & 0.541 & 0.2 & 0.301 & -0.18 & 0.493 \\
\hline River & 75 & 22.1 & 0.5 & 0.28 & 1.09 & 0.075 & 1.08 & 0.031 \\
\hline \multicolumn{9}{|c|}{ Water Per Day } \\
\hline Twice & 151 & 44.4 & & & & & & \\
\hline Once & 189 & 55.6 & 0.06 & 0.603 & -0.05 & 0.648 & 0.24 & 0.036 \\
\hline \multicolumn{9}{|c|}{ Hygiene } \\
\hline Good & 54 & 15.9 & & & & & & \\
\hline Medium & 233 & 68.5 & 0.19 & 0.328 & -0.22 & 0.091 & -0.26 & 0.096 \\
\hline Poor & 53 & 15.6 & 0.6 & 0.021 & -0.05 & 0.864 & -0.6 & 0.008 \\
\hline \multicolumn{9}{|c|}{ Deworm Per Year } \\
\hline Three & 89 & 26.2 & & & & & & \\
\hline Twice & 195 & 57.4 & 0.28 & 0.08 & -0.15 & 0.228 & -0.29 & 0.035 \\
\hline Once & 56 & 16.5 & -0.04 & 0.843 & -0.27 & 0.145 & -0.3 & 0.079 \\
\hline \multicolumn{9}{|c|}{ Herd Size } \\
\hline Below 6 & 229 & 67.4 & & & & & & \\
\hline 6 to 10 & 82 & 24.1 & -0.4 & 0.007 & 0.04 & 0.781 & 0.35 & 0.012 \\
\hline Above 10 & 29 & 8.5 & -0.51 & 0.01 & -0.3 & 0.076 & 0.75 & 0 \\
\hline Constant & & & -1.36 & 0.002 & -0.94 & 0.037 & -0.85 & 0.033 \\
\hline
\end{tabular}

Note: Reproductive problems (RFM, repeat breeding, prolapse, abortion, stillbirth), GIT (diarrhea, indigestion, foreign material ingestion, bloat, constipation, and acidosis).

\section{Discussion}

In the current study, a total of 340 dairy herds which contain lactating (573), pregnant (262), dry, (76), and heifers (279) were included. In these herds exotic, cross, and local breeds were involved which had exotic (16\%), cross (33\%), and local (51\%). The major health problems and constraints in farms in and around Hawassa were LSD, mastitis, milk fever, diarrhea, FMD, respiratory problems, bloat, and repeat breeding. Similarly, lameness, blind teat, teat trauma, uterine and vaginal prolapsed, dystocia, RFM, ectoparasites, indigestion, and others were found to be minor health problems of the dairy cows. The prevalence of mastitis $(25.3 \%)$ in the current study was comparable with the reports done in dairy farms of Addis Ababa (21.2\%) by Tilahun, et al. [24], and Holetta town (22.4\%) by Mekibib, et al. [25]. But it is lower than the reports made by Duguma, et al. [26] in Jimma Town (35\%), by Tebug, et al. [27] in Malawi (39.3\%), and reports by Katsande, et al. [28] from Zimbabwe (49.3\%). This variation might be due to similar a study designed, the difference in herd size, farming system, geographical location, hygienic conditions, and the breed of the animals. But the prevalence of mastitis at cow level (14.5\%) was lower than the results of Fasil, et al. [23] in Hawassa town (20.4\%), Birhanu [29] in Dire Dawa Administrative Council and Eastern Hararghe Zone 
(19.8\%), and Workineh, et al. [30] in two major state-owned dairy farms (21\%) at Debre Zeit. But the present study is higher than the reports done in different dairy farms in Hawassa town (4.9\%) by Moges, et al. [31], in and around Mekelle (6.55\%) by Wudu [32] and in central high lands of Ethiopia (6.6\%) by Mungube, et al. [33] at cow level.

This variation might be due to the study area, the sample population, hygienic condition, and the management skills of the owners. While it was comparable in the reports done in southern Ethiopia (11.9\%) by Biffa, et al. [34]. The prevalence of RFM $(13.2 \%)$ in this study was higher than the reports done by Lobago, et al. [12] in Selalle which was 5.4\% and lower than the reports done by Abuom [35] in Kiambu District, Kenya which was $26.6 \%$ and comparable with the reports done in Mekelle by Regassa, et al. [36] which was $15.8 \%$ at the herd level. But the prevalence (5.5\%) at animal level was comparable with the reports done by Molalegne, et al. [21] in and around Bedelle, which was $8.6 \%$ and in Arsi zone by Degefa, et al. [37] which was $8.3 \%$. Yet, this was lower than the reports done in and around Nazareth town (12.91\%) by Gizaw, et al. [38], and under Small-holding in Addis Ababa (17\%) by Abreham, et al. [39]. But the present study is higher when compared with the report done by Getachew, et al. [40] in Adama District having a prevalence of $0.8 \%$. The variation in the prevalence of RFM might be attributed to the difference in nutritional status and management factors. Uterine paresis, abortion, stress, late or premature birth, dystocia, twinning, infections, seasonal and hormonal disorders, immune suppression vitamin, and mineral deficiencies have been identified as causes of RFM by Beagley, et al. [41]. In this study, the prevalence of clinical FMD (16.5\%) was lower than the reports done by Misgana, et al. [42] in Bale (two districts and one dairy farm) was $21.59 \%$ and Tesfaye [43] who reported the prevalence done $21 \%$ in Borana pastoral area. Additionally, at the animal level, the prevalence of the current study (9.2\%) was lower than the results (17.7\%) by Haftu, et al. [44] in Eastern Zone of Tigray, Ayelet, et al. [45] in Guji zone in Oromia (32.7\%) and Yeka district of Addis Ababa, with the prevalence of $30 \%$.

The variation might be the season and the degree of outbreaks, production systems, and communal usage of facilities. The prevalence of repeat breeding (41.8\%) in the current study is higher than the reports done (26.8\%) by Dinka [46] in and around Asella town, (21.8\%) by Mekonnen (2000) from Adama district and 8.9\% prevalence rate reported by Gizaw, et al. [38]. While the prevalence at cow level (15.1\%) was compared with the results of Fasil, et al. [23] which was $13 \%$ in Hawassa, Haile, et al. [47] in urban and per urban area of Hosanna which was $13.08 \%$ and higher than the results were done by Hadush, et al. [48] from central Ethiopia having a prevalence of $11.4 \%$. Repeated breeding can be caused by several factors, including sub-fertile bulls, endocrine imbalance, malnutrition, reproductive tract infections, and poor management practices such as wrong time of insemination or faulty heat detection, inappropriate semen handling and insemination techniques [49]. In addition to these, communal use of bulls for natural services is also considered as contributing factor. Hence the difference between the findings of the current study and previous reports may be attributed to the above-mentioned factors. The prevalence of LSD in selected districts of North-eastern Ethiopia (Tigray and the Afar Regional States) conducted by Birhanu [50] reports done had a higher herd prevalence of (51\%) in Afar than the present study which was $42.6 \%$ at herd level and higher than the results (37\%) done in Tigray Region and Jimma Town 13\% by Duguma, et al. [26]. But at the individual animal level, the prevalence of LSD (18.6\%) in the current study is closely agreed with the results of Ayelet, et al. [45] in Adama (15.38\%) and higher than the reports in Wenji (10.26\%). But it was lower than reports done by Fasil, et al. [23] in Hawassa town, which was $30.1 \%$. This variation might be due to the environment, production system, breed of the animal, the size of the herd, and management system and vaccination status of the animal. Each disease occurrence in the herd level showed that in the herd at list one animal was diseased during the study time. The prevalence of milk fever (22.4) in herd level was higher than the reports done by Abuom [35] in Kiambu District, Kenya which was $13 \%$. But, at the animal level, the prevalence $(10.3 \%)$ recorded in the current study is lower than the result (17.5\%) reported by Fasil, et al. [23] in Hawassa town.

This difference might be management, type of breed involved, study population, and calcium feed supplements. Most of the literature suggests that when the incidence of milk fevers increases above $(10 \%)$ in their third or later lactation, considerations should be given to a specific control program. Therefore, these results indicated that control methods are required to avoid loss due to milk fever $[8,11,51]$. This is caused by a severe deficiency of metabolizable calcium ion in the circulation and is attributed due to several risk factors. Among the GIT problems, diarrhea (29.1\%), bloat $(16.5 \%)$, indigestion (12.6\%), foreign material ingestion (10.9\%), constipation (6.2) and acidosis (4.2\%) were recorded in this study. The prevalence of bloat (16.5) in this study is higher than the reports done in Bahir Dar by Asmare, et al. [52] which was 5.2 $\%$. But the cow level prevalence of bloat (5.5\%) in the current study is comparable with the finding of Fasil, et al. [23] who reported a $4.5 \%$ prevalence. However, the animal level prevalence of diarrhea $(9.2 \%)$ in this study is higher than the previous report $6.3 \%$ from the same study area by Fasil, et al. [23]. Other health problems observed with lower prevalence such as abortion, prolapsed, dystocia, lameness, ectoparasites, blind teat, and teat trauma are comparable to reports elsewhere. The prevalence of abortion (5\%) in the current study is in agreement with the $3.2 \%, 5.3 \%$, and $6.3 \%$ reported by Ebrahim, et al. [53-55] from Kombolcha, Holetta, and Hawassa, respectively. But it is lower than the reports (14.6\%) by Dinka [46] in and around Asella, (13.9\%) by Molalegne, et al. [21] in and around Bedelle and in Borana by Benti, et al. [56] 
which was $12.2 \%$. The animal level prevalence of abortion $(2.6 \%)$ is comparable to $4.8 \%$ prevalence by Wujira, et al. [57] in Wolaita Sodo, $2.56 \%$ by Haile, et al. [47] in urban and per urban area of Hosanna and lower than the reports done (5.8\%) in the central zone of Tigray region by Weldegebrial [58].

This variation might be due to differences in occurrences of infectious diseases, production systems, management practices, and study methodology. Infectious diseases such as FMD and LSD had a significant association with the risk factors such as crossbreed, river, drank water once per day, poor hygiene, twice deworming per year, and herds which contain above 5 numbers of animals. These diseases had highly significant with herd size from 6 to 10 and above 10 animals. From the study, when the numbers of animals increased in the herd the occurrence of infectious diseases increases. These were due to the high transmissible ability of the diseases through contact, aerosols, and other communal materials. The crossbreed had a significant association with infectious diseases when compared with the exotic breed. The river also had a significant association with these diseases than tap water drinkers. Such infectious disease transmission could transmit through contaminated and infected water. Infectious diseases also had a significant association with hygienic condition.

\section{Conclusion and Recommendations}

The current study revealed a wide occurrence of major health problems of dairy cows in and around Hawassa city, Southern Ethiopia. LSD, repeat breeding, mastitis, milk fever, FMD, diarrhea, bloat, and respiratory problems were among the major health problems of dairy cows. Other diseases such as RFM, dystocia, prolapsed, blind teat, and teat trauma, lameness, indigestion were found low. The potential risk factors associated with disease occurrences in the study area includes breed, herd size, farming (production) system, water sources and frequency of providing water per day, housing, frequency of deworming per year, and hygienic conditions. In conclusion, provide a clean, suitable, and minimal-stress environment. There should be proper animal management, cleanliness, and good hygiene on dairy farms. Improving veterinary services with respect to parasitic control and adequate vaccination. There should be routine and periodical examination of cow during the postpartum period.

\section{References}

1. Getachew Y, Lemma A, Fesseha H (2020) Assessment on reproductive performance of crossbred dairy cows selected as recipient for embryo transfer in urban setup Bishoftu, Central Ethiopia. Int J Vet Sci Res 6(1): 080-60.

2. (2017) Central Statistical Agency. Report on livestock and livestock characteristics. The Federal Democratic Republic of Ethiopia, Private Peasant Holdings, Statistical Bulletin 570. Addis Ababa, Ethiopia: CSA.

3. Dabale SA, Kerorsa GB, Ahmed WM (2020) Prevalence of Major Reproductive Disorders of Dairy Cows in Hawassa City, Ethiopia. Journal of Reproduction and Infertility 11(1): 08-13.
4. Fekadu A, Kassa T, Belehu K (2011) Study on reproductive performance of Holstein-Friesian dairy cows at Alage dairy farm, Rift Valley of Ethiopia. Tropical animal health and production 43(3): 581-586.

5. Dawit F, Fesseha H (2020) Assessment of Major Reproductive Health Problems of Dairy Cows in Dairy Farms of Wolaita Sodo District, Southern Ethiopia. J Vet Med Res 7(4): 1196.

6. Tegegne A, Gebremedhin B, Hoekstra D, Belay B, Mekasha Y (2013) Smallholder dairy production and marketing systems in Ethiopia: IPMS experiences and opportunities for market-oriented development.

7. Felleke G (2003) Milk and dairy products, post-harvest losses and food safety in Sub-Saharan Africa and the near east. A review of the small scale dairy sector-Ethiopia FAO Prevention of Food Losses Programme FAO, Rome, Italy.

8. Weldeyohanes G, Fesseha H (2020) Dystocia in Domestic Animals and its Management. Int J Phar \& Biomedi Rese 7(3): 1-11.

9. (2007) ILRI. International Livestock Research Institute (ILRI) annual report of markets that work making a living from livestock. Nairobi, Kenya.

10. Mengistu A (2005) Feed Resources Base of Ethiopia: Status, limitations and opportunities for integrated development. ESAP Proceedings pp. 377.

11. Hadgu A, Fesseha H (2020) Reproductive biotechnology options for improving livestock production: A review. Adv Food Technol Nutr Sci Open J 6(1): 13-20.

12. Lobago F, Bekana M, Gustafsson H, Kindahl H (2007) Longitudinal observation on reproductive and lactation performances of smallholder crossbred dairy cattle in Fitche, Oromia region, central Ethiopia. Tropical Animal Health and Production 39(6): 395-403.

13. Fesseha H (2020) Clinical and Sub-Clinical Endometritis and its Impact in Reproductive Performance of Cattle: A Review. Corpus J Vet Dairy Sci 1(1): 1005.

14. Thomsen PT, Kjeldsen AM, Sørensen JT, Houe H (2004) Mortality (including euthanasia) among Danish dairy cows (1990-2001). Preventive veterinary medicine 62(1): 19-33.

15. Hossein Zadeh NG (2013) Effects of main reproductive and health problems on the performance of dairy cows: a review. Spanish Journal of Agricultural Research 11(3): 718-735.

16. Mee JF (2008) Prevalence and risk factors for dystocia in dairy cattle: A review. The Veterinary Journal 176(1): 93-101.

17. Mengsitie T (2007) Characterization of cattle milk and meat production, processing and marketing system in Metema district, Ethiopia: Hawassa University.

18. Nibret M (2012) Study on reproductive performance of crossbred dairy cows under small holder conditions in and around Gondar, North Western Ethiopia. Journal of Reproduction and Infertility 3(3): 38-41.

19. Radostits O, Gay C, Hinchcliff K, Constable P, Jacobs D, et al. (2007) Veterinary medicine: A textbook of the diseases of cattle, sheep, pigs, goats, and horses. London: Saunders.

20. Fesseha H, Aliye S, Mathewos M, Kifle T (2020) Chemical and Drug Use in Dairy Farms of Hawassa Town, Southern Ethiopia. Public Health Open J $5(1): 1-7$.

21. Molalegne B, Shiv P (2011) Study on major reproductive health problems in indigenous and cross breed cows in and around Bedelle, South West Ethiopia. Journal of Animal and Veterinary Advances 10(6): 723-727.

22. Thrusfield M (2018) Veterinary epidemiology: John Wiley \& Sons.

23. Fasil N, Juta S, Sheferaw D (2016) Major health challenges of dairy cattle in Hawassa town SNNPRS, Ethiopia. Vet Sci Technol 7: 5. 
24. Tilahun A, Aylate A (2015) Prevalence of bovine mastitis in lactating cows and its public health implications in selected commercial dairy farms of Addis Ababa. Global Journal of Medical Research (G) 15(2).

25. Mekibib B, Furgasa M, Abunna F, Megersa B, Regassa A (2010) Bovine mastitis: Prevalence, risk factors and major pathogens in dairy farms of Holeta Town, Central Ethiopia. Veterinary world 3(9): 397-403.

26. Duguma B, Kechero Y, Janssens GP (2012) Survey of major diseases affecting dairy cattle in Jimma town, Oromia, Ethiopia. Global veterinaria 8(1): 62-66.

27. Tebug SF, Njunga GR, Chagunda MG, Wiedemann S (2012) Health constraints and farm management factors influencing udder health of dairy cows in Malawi. Journal of Agricultural Science 4(6): 136.

28. Katsande S, Matope G, Ndengu M, Pfukenyi DM (2013) Prevalence of mastitis in dairy cows from smallholder farms in Zimbabwe. Onderstepoort Journal of Veterinary Research 80(1): 1-7.

29. Birhanu S (1997) Bovine in dairy farm in Dire Dawa Administrative council and Western Harareghe zone prevalence, isolation and invitro anti microbial susceptibility study [DVM Thesis]. Addis Ababa: Addis Ababa University, Ethiopia.

30. Workineh S, Bayleyegn M, Mekonnen H, Potgieter L (2002) Prevalence and aetiology of mastitis in cows from two major Ethiopian dairies. Tropical Animal Health and Production 34(1): 19-25.

31. Moges N, Hailemariam T, Fentahun T, Chanie M, Melaku A (2012) Bovine mastitis and associated risk factors in small holder lactating dairy farms in Hawassa, Southern Ethiopia. Global Veterinaria 9(4): 441-446.

32. Wudu T (1999) Study on Bovine mastitis in and around Mekelle. DVM thesis, Faculty of Veterinary Medicine, Addis Ababa University, Ethiopia.

33. Mungube E, Tenhagen BA, Regassa F, Kyule M, Shiferaw Y, et al. (2005) Reduced milk production in udder quarters with subclinical mastitis and associated economic losses in crossbred dairy cows in Ethiopia. Tropical animal health and production 37(6): 503-512.

34. Biffa D, Debela E, Beyene F (2005) Prevalence and risk factors of mastitis in lactating dairy cows in Southern Ethiopia. International Journal of Applied Research in Veterinary Medicine 3(3): 189-198

35. Abuom T, Njenga M, Wabacha J, Tsuma V, Gitau G (2012) Incidence and risk factors of periparturient conditions in smallholder dairy cattle herds in Kikuyu Division of Kiambu District, Kenya. Ethiopian Veterinary Journal 16(2): 85-102.

36. Regassa T, Ashebir G (2016) Major factors influencing the reproductive performance of dairy farms in Mekelle City, Tigray, Ethiopia. Journal of Dairy, Veterinary \& Animal Research 3(4): 145-149.

37. Degefa T, Duressa A, Duguma R (2011) Brucellosis and some reproductive problems of indigenous Arsi cattle in selected Arsi zones of Oromia regional state, Ethiopia. Global Veterinaria 7(1): 45-53.

38. Gizaw Y, Bekana M, Abayneh T (2007) Major reproductive health problems in smallholder dairy production in and around Nazareth town, Central Ethiopia. Priory Medical Journal Online.

39. Abreham H, Tesfu K, Mulugeta M, Yilkal A (2010) Major reproductive disorders in crossbred dairy cows under smallholding in Addis Ababa milkshed, Ethiopia. World Journal of Agricultural sciences 6(4): 412418.

40. Getachew E, Nibret M (2014) Major reproductive health disorders in cross breed dairy cows in Ada'a district, East Shoa, Ethiopia. Global Veterinaria 13(4): 444-449.
41. Beagley J, Whitman K, Baptiste KE, Scherzer J (2010) Physiology and treatment of retained fetal membranes in cattle. Journal of veterinary internal medicine 24(2): 261-268.

42. Misgana D, Yasmin J, Ahmed I, Addisalem H (2013) Sero-prevalence of foot and mouth disease of cattle in Bale Zone, Oromiya regional state, Ethiopia. Global Veterinaria 11(1): 59-64.

43. Tesfaye R (2006) Paticipatory appraisal and sero-prevalence study of Foot-and-Mouth disease in Borana Pastoral system, Ethiopia: MSc thesis, Addis Ababa Univ, Ethiopia.

44. Haftu B, Asresie A, Haylom M (2014) Assessment on major health constraints of livestock development in eastern zone of tigray: The case of "gantaafeshum woreda" northern Ethiopia. J Vet Sci Technol 5: 174.

45. Ayelet G, Gelaye E, Negussie H, Asmare K (2012) Study on the epidemiology of foot and mouth disease in Ethiopia. Rev Sci Tech 31(3): 789-798.

46. Dinka H (2013) Major reproductive disorders of dairy cows in and around Asella town, Central Ethiopia. Journal of Veterinary Medicine and Animal Health 5(4): 113-117.

47. Haile A, Tsegaye Y, Tesfaye N (2014) Assessment of major reproductive disorders of dairy cattle in urban and per urban area of Hosanna, Southern Ethiopia. Animal and Veterinary Sciences 2(5): 135-141.

48. Hadush A, Abdella A, Regassa F (2013) Major prepartum and postpartum reproductive problems of dairy cattle in Central Ethiopia. Journal of Veterinary Medicine and Animal Health 5(4): 118-123.

49. Arthur G, Noakes D, Parkinson T, England G (2001) Arthur's Veterinary Reproduction and Obstetrics. Philadelphia: WB Saunders Ltd. pp. 864.

50. Birhanu T (2012) Assessments of the risk factors and financial impacts of LSD in selected districts of Tigray and Afar Regional States [MSc thesis]. Mekelle: Mekelle University.

51. Horst RL (1986) Regulation of calcium and phosphorus homeostasis in the dairy cow. Journal of Dairy Science 69(2): 604-616.

52. Asmare Z, Ferede Y, Tesfa A (2017) Survey on major diseases affecting dairy cattle in Bahir Dar Daiy farms, North Western Ethiopia. JEZS 5(2): 1121-1124.

53. Ebrahim O (2003) Study on major reproductive health problems of small-holder dairy farms in and around Kombolcha [DVM Thesis]. Addis Ababa: Addis Ababa University.

54. Shiferaw Y (1999) Fertility status of dairy cows under different production systems in Holetta central Highland of Ethiopia [MSc Thesis]. Debrezeit: Addis Ababa University and Freie Universitat Berlin.

55. Kassahun M (2003) Major clinical reproductive problems of smallholder dairy cows in and around Awassa [DVM thesis]. DebreZeit, Ethiopia: Addis Ababa University.

56. Benti AD, Zewdie W (2014) Major reproductive health problems of indigenous Borena cows in Ethiopia. Journal of Advanced Veterinary and animal research 1(4): 182-188.

57. Wujira E, Nibret M (2016) Major Reproductive Health Problems in Dairy Cows in Wolaita Sodo Town in Selected Farms. European Journal of Biological Science 8(3): 85-90.

58. Weldegebriall B (2015) Assessment of major reproductive problems of dairy cattle in selected sites of central Zone of Tigrai Region, northern Ethiopia: Mekelle Univeristy. 
ISSN: 2574-1241

DOI: $10.26717 / B J S T R .2020 .30 .004905$

Haben Fesseha. Biomed J Sci \& Tech Res

(C) (P) This work is licensed under Creative

Submission Link: https://biomedres.us/submit-manuscript.php

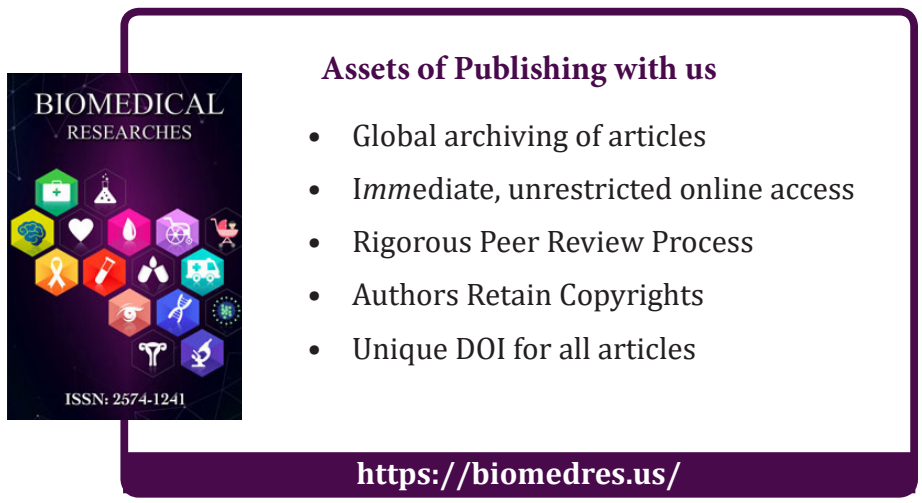

